\title{
Further Views on the Basement Membrane Controversy
}

\author{
L. O. Simpson \\ Department of Pathology, University of Otago Medical School, Dunedin, New Zealand
}

Although it has been claimed often that increased basement membrane thickness is an important factor in diabetic nephropathy, there is no direct evidence that it is associated necessarily with increased permeability or elevated glomerular filtration rate [1] and it should be noted that both changes could follow increased hydrostatic pressure. Hydrostatic pressure and capillary wall structure were thought to be involved in the extravasation of plasma proteins in diabetic microangiopathy [2]. The pressure dependence of human skin capillary permeability was demonstrated by Landis more than 40 years ago [3]. More recently, increased filtration pressure was linked causally with the increased glomerular filtration rate and elevated filtration fraction of diabetic nephropathy [4]. On the other hand, Viberti [5] expressed the view that basement membrane thickness and permeability to plasma proteins were 'somewhat independent'.

Recent accepted concepts of basement membrane permeability are based upon a pore theory [6] in which the basement membrane is considered as a semi-permeable membrane containing cylindrical pores of $3.5-4.2 \mathrm{~nm}$ radius, or rectilinear slits of $3.6 \mathrm{~nm}$ half width [7]. The permeability of the membrane is believed to be determined by the interaction of particles with the anionic charge barrier on the basement membrane and endothelium $[8,9]$.

Alternative concepts of basement membrane structure treat it either as a hydrated gel through which filtration occurs by diffusion [10]: or a 'felted fibril' concept in which increased permeability was explained by the slackening of the fibrils when hydrostatic pressure fell [11]. It is noteworthy that these concepts provide no explanation of how cells or larger motile parasite larvae pass through basement membranes without leaving evidence of their passage.

In 1980 a new concept was put forward that basement membranes are thixotropic gels which are ca- pable of undergoing localised, reversible deformation under the effect of pressure [12]. Such gels would have the dispersed phase disposed as an irregular lattice which contained the dispersion medium (water). Solutions and small particles of about $2 \mathrm{~nm}$ radius or less would pass freely through the lattice, but larger particles would be able to traverse the membrane only if they had sufficient energy to deform the lattice, which reformed after the passage of the particles. In a recent study by Ota et al. [13] ultra-high magnification electron microscopy of unfixed glomerular basement membrane has revealed a sponge-like lattice without large pores or fibrils but which had interstices of similar size to that proposed in the thixotropic gel model [12].

Technical difficulties have prevented direct assessment of pressure-permeability relationships of basement membranes although indirect observations provide support for the idea that basement membranes are pressure dependent. Stolte et al. showed a straight line relationship between pressure and the amount of albumin filtered in perfused rat kidneys [14]. Mice with spontaneous lupus nephritis developed high molecular weight proteinuria in association with elevated systolic blood pressure [15]. Mogensen found that the use of antihypertensive drugs inhibited the progression of diabetic nephropathy as interpreted by altered glomerular filtration rate in five out of six patients [16].

In serial studies of diabetic urines, we have observed that some samples contained a range of plasma proteins, demonstrable by the use of sodium dodecyl sulphate polyacrylamide gel electrophoresis. Similar urinary protein profiles have been found in other types of human nephropathy, in murine lupus nephritis and in exercise proteinuria induced in subjects with normal renal function [unpublished observations]. The similarity of the protein profiles may be 
compatible with the concept that proteinuria is not necessarily an indication of glomerular damage, nor of permanently altered glomerular basement membrane permeability. One interpretation is that proteinuria indicates a higher intra-glomerular pressure than normal at the time of filtration and the larger the plasma proteins in the urine, the higher has been the intraglomerular pressure.

The proteinuria of exercise appears to be caused by increased pressure on the kidney or on the renal vessels due to increased intra-abdominal pressure, or to raised intra-vascular pressure resulting from vascular smooth muscle contraction induced either by sympathetic nerve stimulation or by catecholamines [17]. We have found that 14-17 year old gymnasts produce different urinary protein profiles depending upon the type of body movements involved in their training exercises [unpublished observations]. Some of the protein profiles resembled those associated with kidney pathology and were similar to those found in postcompetition samples from participants in an international gymnastic contest, and in after-match samples from university rugby football players. Several recent reports have described increased catecholamine production during competitive sports, and Starr [18] found in rabbits that proteinuria followed adrenaline injection. While it is likely that catecholamines are involved in the exercise-induced rise in blood pressure [19], and in the proteinuria of diabetics [20], it is possible that the most significant cause of diabetic proteinuria is the impedance to the flow of viscous blood in the efferent arteriole. Elevated glomerular filtration rate in diabetics was considered by Ditzel and Junker [1] to be due to increased filtration pressure as a result of constricted efferent arterioles. Earlier workers [21, 22] expressed the opinion that normal glomerular function was determined by the tone of the smooth muscles of the efferent arteriole. However the relative ease with which transient proteinuria showing pathological-type urinary protein-profiles can be produced, irrespective of the cause of the increased filtration pressure, indicates the functional versatility of the glomerular filter.

Whole human blood is thixotropic [23] and this feature has been characterised in mathematical terms [24]. Because of filtration, blood in the efferent arteriole shows maximum haemoconcentration, maximum viscosity and increased resistance to flow. The thixotropic nature of blood ensures that a fall in flow rate will decrease shear rate, producing an increase in viscosity which will decrease further the flow rate. Unless this vicious cycle is broken by an increase in intravascular pressure capable of restoring normal flow rate, stasis will develop. Resolution of stasis would occur only if intravascular pressure is raised to a level which provides an adequate yield shear stress [25].

Diabetes under poor metabolic control is associated with increased plasma viscosity, impaired red cell deformability and increased red cell aggregation [26-30]. Resistance to flow offered by viscous blood in the efferent arteriole leads to an intra-glomerular back pressure, resulting in albuminuria or high molecular weight proteinuria if the back pressure is high enough. Similar back pressure effects occur in the smallest tissue capillaries resulting in the extravasation of plasma proteins. This has been demonstrated in diabetics by immunofluorescent techniques [31, 32]. Ultrastructural changes in glomeruli of diabetics include increased basement membrane thickness and mesangial expansion. It is likely that the basement membrane change is benign [33], but the effects of mesangial expansion on vascular patency are potentially pathogenic because it will eventually so reduce the lumina that blood flow is impeded. When this change is associated with increased blood viscosity, glomerulosclerosis can be expected. Diffuse glomerulosclerosis thus results from the stasis of hyperviscous blood in glomerular vessels with reduced patency. This may be a simplification of a more complex process but the proposed mechanism offers a reasonable explanation of how entire glomeruli are quickly rendered obsolete. While good metabolic control may prevent diabetic nephropathy by reducing the proliferation of mesangial matrix and by maintaining normal blood viscosity, either factor out of control may cause renal dysfunction.

\section{References}

1. Ditzel J, Junker K (1972) Abnormal glomerular filtration rate, renal plasma flow and renal protein excretion in recent and short-term diabetics. Br Med J 2: 13-19

2. Leading article (1977) Pathogenesis of diabetic microangiopathy. Br Med J 1:1555-1556

3. Landis EM (1934) Capillary pressure and capillary permeability. Physiol Rev 14: 404-481

4. Westberg NG (1980) Diabetic nephropathy. Pathogenesis and prevention. Acta Endocrinol 94 (Suppl 238): 85-100

5. Viberti GC (1979) Early functional and morphological changes in diabetic nephropathy. Clin Nephrol 12:47-53

6. Pappenheimer JR, Renkin EM, Borrero LM (1951) Filtration, diffusion and molecular sieving through peripheral capillary membranes. Am J Physiol 167: 13-146

7. Landis EM, Pappenheimer JR (1963) Exchange of substances through the capillary walls. In: Hamilton WF, Dow P (eds) Handbook of physiology, Section 2. American Physiology Society, Washington DC, pp 971-1034

8. Bohrer MP, Baylis C, Humes HD, Robertson CR, Brenner BM (1978) Permselectivity of the glomerular capillary wall: facilitated filtration of circulating polycations. J Clin Invest 61: $72-78$

9. Caulfield JP, Farquhar MG (1978) Loss of anionic sites from 
the glomerular basement membrane in aminonucleoside nephrosis. Lab Invest 39: 505-512

10. Chinard FM (1952) Derivation of an expression for the rate of formation of glomerular fluid (GFR). Applicability of certain physical and physico-chemical concepts. Am J Physiol 171: $578-586$

11. Ryan GB, Karnowsky M (1976) Distribution of endogenous albumin in the rat glomerulus: role of haemodynamic factors in glomerular barrier function. Kidney Int $9: 36-45$

12. Simpson LO (1980) Basement membranes and biological thixotropy: a new hypothesis. Pathology 12:377-389

13. Ota Z, Makino H, Takaya Y, Ofuji T (1980) Molecular sieve in renal glomerular and tubular basement membranes as revealed by electron microscopy. Renal Physiol 3:272-279

14. Stolte H, Schurek HJ, Alt JM (1979) Glomerular albumin filtration: a comparison of micropuncture studies in the isolated perfused rat kidney with in vivo experimental conditions. Kidney Int 16:377-384

15. Simpson LO (1980) A mouse model of spontaneous renal hypertension. Blood pressure, heart weight, kidney weight and proteinuria relationships in NZB X OUW $F_{1}$ hybrid female mice. Pathology 12:347-357

16. Mogensen CE (1980) Antihypertensive treatment inhibiting the progression of diabetic nephropathy. Acta Endocrinol 94 (Suppl 238): 103-111

17. Poortmans JR (1977) Exercise and renal function. Exerc Sport Sci Rev 5:255-294

18. Starr I (1926) The production of albuminuria by renal vasoconstriction in animals and man. J Exp Med 43:31-51

19. McMillan DE (1979) Exercise and diabetic microangiopathy. Diabetes 28: 103-106

20. Mogensen CE, Vittinghus E (1975) Urinary albumin excretion during exercise in juvenile diabetes. A provocation test for early abnomalities. Scand J Clin Lab Med 35:295-300

21. Winton FR (1937) Physical factors involved in the activities of the mammalian kidney. Physiol Rev 17:408-435

22. Smith HW, Chasis H, Goldring W, Ranger HA (1940) Glomerular dynamics in the normal human kidney. J Clin Invest 19: $751-764$
23. Dintenfass L (1964) Rheology in medicine and surgery. Med J Aust 2: $926-930$

24. Huang CR, Siskovic N, Robertson RW, Fabisiak W, Smitherberg EH, Copley AL (1975) Quantitative characterisation of thixotropy of whole human blood. Biorheology 12:279-282

25. Merrill EW, Margett WG, Cokelet GR (1963) Influence of plasma proteins on the rheology of human blood. In: Copley AL (ed) Proceedings of the Fourth International Congress of Rheology. Interscience Publishers, New York London Sydney, pp 601-611

26. Skovberg F, Nielsen AaV, Schlictkrull K, Ditzel J (1966) Blood viscosity in diabetic patients. Lancet 1: 129-131

27. Schmid-Schonbein H, Volger E (1976) Red cell aggregation and red cell deformability in diabetes. Diabetes 25:897-902

28. Barnes AJ, Locke P, Scudder PR, Dormandy TL, Dormandy JA, Slack J (1977) Is hyperviscosity a treatable component of diabetic microcirculatory disease? Lancet 2: 789-791

29. Lowe GDO, Lowe JM, Drummond MM, Reith S, Belch JJF, Kesson CM, Wylie A, Foulds WS, Forbes CD, MacCuish AC, Manderson WG (1980) Blood viscosity in young male diabetics with and without retinopathy. Diabetologia 18:359-363

30. Dintenfass L, Davis E (1977) Blood viscosity factors and capillary abnormalities in diabetes. Bibl Anat 16:425-427

31. Miller K, Michael AF (1976) Immunopathology of renal extracellular membranes in diabetes mellitus. Specificity of tubular basement membrane immunofluorescence. Diabetes 25: 701-708

32. Cohn RA, Mauer SM, Barbosa J, Michael AF (1978) Immunofluorescence studies of skeletal muscle extracellular membrane in diabetes mellitus. Lab Invest 39: 13-16

33. Ganda OP, Soeldner JS (1980) Capillary basement membrane thickness in monozygotic twins. Lancet 2: 650 (Letter)

Dr. L. O. Simpson

Pathology Department

Medical School

P. O. Box 913

Dunedin, New Zealand 